\title{
Etude cytogénétique des taureaux d'un centre d'insémination artificielle en Roumanie
}

\author{
Brîndusa Elena LIVESCU \\ Laboratoive de Génétique, Institut de Recherches pour l'Élevage des Bovins, \\ Corbeanca, Ilfov, Roumanie
}

\begin{abstract}
Soixante-six taureaux de trois races (Holstein Friesian, Charolais et Brune) d'un centre d'insémination artificielle ont été examinés.

Un animal de race Charolais a été trouvé porteur de translocation I/29. L'étude cytogénétique sur 22 descendants de ce taureau a donné la possibilité de connaître le mécanisme de transmission héréditaire de cette anomalie chromosomique.

Un taureau Holstein Friesian a été porteur de chimerisme XX/XY.

Cinq taureaux ont présenté un pourcentage élevé des cellules tetraploïdes (20 p. cent). On discute les implications possibles de ces anomalies chromosomiques.
\end{abstract}

\section{The influence of the $1 / 29$ Robertsonian translocation on fertility and milk production of Swiss Simmental cows}

\author{
B. ZAHNER \\ Klinik fur Nutztiere und Pferde der Universitat, \\ Bern GH 3012 Bern Switzerland
}

Les caryotypes de ro4 $_{4}$ filles de deux taureaux “d'insémination artificielle ontété examinés. Quelques paramètres de fertilité et de production laitière de ces demi-sours ont été comparés entre les animaux avec et sans translocation. La translocation semble avoir une petite influence, qui est plutôt négative sur la fertilité et plutôt positive sur la production laitière.

\section{L'aneuploïdie et la polyploïdie dans les cultures de cellules bovines}

\author{
E. P. CRIBIU et C. P. POPESCU \\ Laboratoire de Cytogénétique, U.N.C.E.I.A.-I.N.R.A., \\ Centre national de Recherches zootechniques, I.N.R.A., \\ 78350 Jouy-en-Josas, France
}

L'étude porte sur la fréquence des cellules polyploïdes et péridiploïdes d'une part parmi $42 \mathrm{I}$ taureaux d'insémination artificielle appartenant à 5 races françaises : Charolaise, MaineAnjou, Limousine, Normande et Frisonne, et d'autre part chez 5 lignées cellulaires embryonnaires reinales parmi lesquelles 3 sont porteuses de la translocation robertsonienne $\mathrm{I} / 29$. La différence enregistrée entre les fréquences des cellules à 59 chromosomes et à $6 \mathrm{r}$ chromosomes dans les cultures de sang périphérique suggèrent l'intervention de deux phénomènes : une perte aléatoire due aux conditions de traitement et une non-disjonction d'un chromosome lors de l'anaphase de la cellule mère. Des différences hautement significatives entre les fréquences des cellules polyploïdes de chaque race bovine ont été observées. 